\title{
Insulin-producing cells in the Drosophila brain also express satiety-inducing cholecystokinin-like peptide, drosulfakinin
}

\author{
Jeannette A. E. Söderberg, Mikael A. Carlsson and Dick R. Nässel *
}

Department of Zoology, Stockholm University, Stockholm, Sweden

\section{Edited by:}

Liliane Schoofs, Catholic University of Leuven, Belgium

\section{Reviewed by:}

Leo T. O. Lee, The University of Hong Kong, China

Samuel S. Ng, The University of Hong Kong, China

\section{*Correspondence:}

Dick R. Nässel, Department of Zoology, Stockholm University, SE-10691 Stockholm, Sweden e-mail:dnassel@zoologi.su.se
Regulation of meal size and assessing the nutritional value of food are two important aspects of feeding behavior. The mechanisms that regulate these two aspects have not been fully elucidated in Drosophila. Diminished signaling with insulin-like peptides Drosophila insulin-like peptides (DILPs) affects food intake in flies, but it is not clear what signal(s) mediates satiety. Here we investigate the role of DILPs and drosulfakinins (DSKs), cholecystokinin-like peptides, as satiety signals in Drosophila. We show that DSKs and DILPs are co-expressed in insulin-producing cells (IPCs) of the brain. Next we analyzed the effects of diminishing DSKs or DILPs employing the Gal4-UAS system by (1) diminishing DSK-levels without directly affecting DILP levels by targeted Dsk-RNAi, either in all DSKproducing cells (DPCs) or only in the IPCs or (2) expressing a hyperpolarizing potassium channel to inactivate either all the DPCs or only the IPCs, affecting release of both peptides. The transgenic flies were assayed for feeding and food choice, resistance to starvation, and for levels of Dilp and Dsk transcripts in brains of fed and starved animals. Diminishment of DSK in the IPCs alone is sufficient to cause defective regulation of food intake and food choice, indicating that DSK functions as a hormonal satiety signal in Drosophila. Quantification of Dsk and Dilp transcript levels reveals that knockdown of either peptide type affects the transcript levels of the other, suggesting a possible feedback regulation between the two signaling pathways. In summary, DSK and DILPs released from the IPCs regulate feeding, food choice and metabolic homeostasis in Drosophila in a coordinated fashion.

Keywords: peptide hormones, insulin signaling, satiety regulation, feeding behavior, food choice, Drosophila melanogaster

\section{INTRODUCTION}

Caloric intake is tightly regulated in animals to ensure energy stores sufficient for daily activity, and, at least in mammals, the nutrient consumption is also controlled to maintain body weight near constancy over extended periods (Woods et al., 2000; Murphy and Bloom, 2006; Murphy et al., 2006; Woods and D'Alessio, 2008; Al-Anzi et al., 2010). Since caloric intake is known to affect body weight, insulin signaling, and healthy life span (Kenyon et al., 1993; McMinn et al., 2000; Tatar et al., 2001, 2003; Broughton et al., 2005; Partridge et al., 2005; Giannakou and Partridge, 2007; Ja et al., 2009; Moran and Dailey, 2009), it is of interest to understand regulation of feeding. In most animals food intake depends on meal size and frequency of meals (Murphy and Bloom, 2006; Woods and D'Alessio, 2008; Al-Anzi et al., 2010; Cognigni et al., 2011), but what mechanisms control initiation, maintenance, and termination of feeding, and how is food quality assessed in relation to hunger? Due to problems in modern society with obesity, diabetes, and other metabolic disorders, large efforts have been made, especially in mammals, to investigate the roles of neuropeptides and peptide hormones in regulation of feeding and metabolism (McMinn et al., 2000; Strader and Woods, 2005; Sandoval et al., 2008; Moran and Dailey, 2009; Barth, 2011).

Although insects have been used quite extensively for analysis of feeding behavior, since the seminal work on the blowfly
Phormia regina (Dethier, 1976), they have only recently been adopted for studies of peptidergic regulation of food choice, food intake, and metabolism. Thus far there is evidence for several peptides acting at different levels in regulation of feeding in insects: leucokinins (Al-Anzi et al., 2010), neuropeptide F (NPF; Wu et al., 2003, 2005a), short neuropeptide F (sNPF; Lee et al., 2004, 2008), insulin-like peptides (Broughton et al., 2010; Cognigni et al., 2011), Hugin derived peptides (Melcher and Pankratz, 2005), sulfakinins (Wei et al., 2000; Maestro et al., 2001; Wu et al., 2003; Downer et al., 2007; Meyering-Vos and Muller, 2007), allatostatins (Aguilar et al., 2003; Hergarden et al., 2012), and sex peptide (Carvalho et al., 2006). It is, however, not yet clear how these peptide signals are coordinated to control the initiation, maintenance, and termination of feeding (see Audsley and Weaver, 2009; Nässel and Winther, 2010). In mammals peptidergic signaling in regulation of feeding and satiety is very complex and involves among others cholecystokinin (CCK), neuropeptide Y, peptide YY, pancreatic polypeptide, leptin, ghrelin, and insulin (Strader and Woods, 2005; Wynne et al., 2005; Murphy et al., 2006; Sandoval et al., 2008; Woods and D'Alessio, 2008; Barth, 2011; Dagher, 2012). Here we investigate the coordinated roles in feeding in Drosophila of the CCK-like Drosophila sulfakinins (drosulfakinins, DSKs), and Drosophila insulin-like peptides (DILPs). 
The reason for targeting these peptides is the observation that a set of median neurosecretory cells (MNCs) in the pars intercerebralis of larval brain of Drosophila express both DSKs and DILPs (Park et al., 2008) and thus may act in a coordinated fashion in regulation of feeding and metabolism. Also, it is of interest to determine the specific role of DSKs in these MNCs since several studies have analyzed the effect of genetically ablating or silencing these cells (see; Broughton et al., 2005; Broughton et al., 2010; Cognigni et al., 2011), and the phenotype obtained after this ablation is likely to be a result of diminishing both types of peptides. In other words, do these MNCs serve functions additional to the known DILP-mediated ones?

In Drosophila and other animals insulin signaling has been implicated in regulation of growth, fecundity, metabolic homeostasis, stress resistance, and longevity (Brogiolo et al., 2001; Wu and Brown, 2006; Baker and Thummel, 2007; Giannakou and Partridge, 2007; Fontana et al., 2010; de la Rosa and de Pablo, 2011; Antonova et al., 2012). Eight genes encoding DILPs are known in Drosophila and are differentially expressed in a stageand tissue-specific manner (Brogiolo et al., 2001; Grönke et al., 2010; Colombani et al., 2012; Garelli et al., 2012). Three of these, encoding DILP2, 3, and 5, are co-expressed in a set of MNCs of the brain designated insulin-producing cells, IPCs (Cao and Brown, 2001; Ikeya et al., 2002; Rulifson et al., 2002; Karpac et al., 2009). These three Dilp genes are under individual transcriptional control, depending on various nutritional, or stress conditions, or genetic manipulations of IPC function (see, e.g., Ikeya et al., 2002; Géminard et al., 2009; Karpac et al., 2009; Broughton et al., 2010; Grönke et al., 2010; Slack et al., 2010; Birse et al., 2011). This is a feature that may indicate that the three DILPs have different functions. On the other hand, the DILPs display a certain degree of functional redundancy and the transcriptional levels of other DILPs increase if one is knocked down (Broughton et al., 2008; Grönke et al., 2010).

Partial genetical ablation of the IPCs in the brain in late larval stages, prolongs lifespan, reduces fecundity, changes both lipid, and carbohydrate metabolism and increases the resistance to both starvation and oxidative stress (Broughton et al., 2005). Ablation of the IPCs in the early larval stages leads to developmental delay, growth retardation, and increased circulating carbohydrate levels (Partridge and Gems, 2002; Broughton et al., 2005). Flies with deleted or inactivated IPCs also display altered feeding behavior (Broughton et al., 2010; Cognigni et al., 2011). The question is to what extent this effect on feeding is due to DILPs or the co-localized DSKs, since ablation or inactivation of the IPCs affect both types of peptides and sulfakinins have been shown to induce satiety (Wei et al., 2000; Maestro et al., 2001; Wu et al., 2003; Downer et al., 2007; Meyering-Vos and Muller, 2007).

Drosulfakinins and sulfakinins of other insects are related to members of the vertebrate CCK peptide family, based on similarities in amino acid sequence and the requirement of a sulfated tyrosyl residue for bioactivity (Nachman et al., 1986a,b, 1988; Nichols et al., 1988; Staljanssens et al., 2011). Also the DSK receptors (CG6857 and CG6881) are considered related to the gastrin/CCK receptors, based on similarities in amino acid sequence and gene organization (Kubiak et al., 2002; Hauser et al., 2006; Janssen et al., 2008; Staljanssens et al., 2011). Like CCK in mammals (Moran et al., 1998; Dockray, 2009; Moran and Dailey, 2009), sulfakinins are satiety-inducing signals in locusts, crickets, cockroaches, and flies (see Maestro et al., 2001; Wu et al., 2003; Downer et al., 2007; Meyering-Vos and Muller, 2007; Wicher et al., 2007; Nichols et al., 2008). The two peptides (DSK-1 and 2) of the D. melanogaster sulfakinin gene (Dsk) have also been shown to play roles in locomotion and odor preferences and a third peptide DSK-0 on the same gene induces crop contractions (Nichols et al., 1988; Duttlinger et al., 2002; Palmer et al., 2007). It should be noted that Dsk and its peptide products are expressed by several other neurons in the Drosophila brain in addition to the IPCs (Nichols, 1992; Nichols and Lim, 1996; Park et al., 2008). However, the IPCs seem to be the only DSK-producing neurons that are neurosecretory with axons terminating in neurohemal areas of the corpora cardiaca, aorta, and anterior intestine (see Nichols and Lim, 1996; Park et al., 2008, unpublished observations). Here, we investigated the functional role of DSKs in the IPCs in comparison with global knockdown of all DSK in the brain. We utilized different sets of Gal4- and UAS-lines in crosses, to elucidate the role of DSKs in relation to DILPs in the IPCs. To manipulate DSK-levels without affecting DILP levels, we utilized a Dsk-RNAi construct, either in all DSK-producing cells (DPCs; Dsk-Gal4) or only the IPCs (Dilp2-Gal4). We also inactivated the IPCs or DPCs with a hyperpolarizing potassium channel. These experiments separate the global role of DSKs in all DPCs and the role of DSKs co-localized with DILPs in IPCs. We tested the transgenic flies in various assays of feeding, food choice, starvation, and for levels of Dilp and Dsk transcripts in fed and starved flies. Our data suggest that DSKs in IPCs are sufficient for regulation of satiety in larvae and adult flies.

\section{MATERIALS AND METHODS}

\section{FLY STRAINS AND HUSBANDRY}

All flies were reared at $25^{\circ} \mathrm{C}$ on a standard yeast/corn meal/agar medium, under 12:12 h light:dark conditions. The following fly lines were used in the experiments: Dsk-Gal4 (Park et al., 2008) donated by Jae H. Park, Knoxville, USA (Park et al., 2008) and Dilp2-Gal4 (Ikeya et al., 2002) originally from Ernst Hafen, Zürich, Switzerland (donated by S. Broughton, Lancaster, UK). These strains were used to drive expression of target genes in the DPCs and the IPCs, respectively, by means of the binary Gal4-UAS (Upstream Activating Sequence) system. To diminish the expression of DSKs, we used a UAS-Dsk-RNAi line (CG18090; Transformant ID14201) obtained from the Vienna Drosophila RNAi Center (VDRC). A UAS-Dilp5-RNAi line (CG32273; Transformant ID 49520) was obtained from VDRC. These transformants have no recorded off targets. Four to six days old adult progeny of the crosses between Gal4 and UAS lines were collected for experiments, and as controls we used these parental strains crossed to $w^{1118}$ flies [from Bloomington Drosophila Stock Centre (BDSC) at Indiana University, Bloomington, IN, USA]. A Dilp2,3,5 mutant (Grönke et al., 2010) was provided by S. Grönke and L. Partridge (London, UK). These Dilp deletions were generated by ends out homologous recombination and shown to be null alleles (Grönke et al., 2010). As wild type controls we used the $w^{1118}$ strain. To inactivate the DPCs or IPCs through membrane hyperpolarization, we employed UAS- $d O r k 1$, a construct with a constitutively 
active $\mathrm{K}^{+}$-channel (Nitabach et al., 2002), obtained from BDSC. In all experiments on adults, only male flies were used.

\section{ELECTRICAL SILENCING OF DPCs AND IPCs}

A means to silence neuronal signaling is to suppress electrical activity in the membrane of the neuron. This can be achieved by expressing potassium channels that remain open even at resting membrane potential, allowing for an increased flux of potassium ions out of the neuron that hyperpolarizes it and prevents it from signaling (Nitabach et al., 2002). We utilized a UAS-dOrk1-line (Nitabach et al., 2002) to express a constitutively activated potassium channel and inactivate either IPCs or DPCs. This method enabled us to silence the cells and affect both DSK and DILPs in the IPCs without ablating the cell, thus avoiding the compensatory developmental mechanisms that might occur when the cells undergo apoptosis.

\section{IMMUNOCYTOCHEMISTRY AND GFP EXPRESSION}

Drosulfakinin localization in the brain was detected using an antiserum against DSK donated by Ruthann Nichols (Ann Arbor, MA, USA). A anti-rabbit antiserum to DILP2 (Cao and Brown, 2001) provided by Mark Brown (Athens, GA, USA) was used to visualize the IPCs. UAS-mCD8-GFP flies crossed with Gal4 drivers to visualize GFP expression in cells in order to perform double-labeling with peptide antisera. A mouse monoclonal antibody to GFP (\#A-11120, Molecular Probes, Invitrogen) or a rat monoclonal antibody to mCD8 (\#MCD0800; Molecular Probes, Invitrogen) were used to amplify the fluorescence intensity of the mCD8-GFP signal.

Fly brains were fixed in $4 \%$ paraformaldehyde (PFA) in $0.1 \mathrm{M}$ sodium phosphate buffer (PB; $\mathrm{pH} 7.4$ ). The dissected brains were incubated with primary antibody diluted in $0.01 \mathrm{M}$ phosphatebuffered saline (PBS; pH 7.4), with $0.25 \%$ Triton-X, and $0.5 \%$ bovine serum albumin (BSA) for 48-72 $\mathrm{h}$. A thorough washing in PBS containing $0.25 \%$ Triton-X (PBS-Tx) was followed by incubation in secondary antibody: Alexa 546-conjugated goat antirabbit antiserum (\#A-11010, Invitrogen) at 1:1500. Specimens were imaged with a Zeiss LSM 510 confocal microscope (Jena, Germany) and processed with Zeiss LSM software and edited for contrast and brightness in Adobe Photoshop CS3 version 10.0.1.

\section{FOOD INTAKE ASSAYS}

Different assays are available for measuring food consumption in Drosophila. We slightly modified the protocol of Al-Anzi et al. (2010). Flies were starved for $18 \mathrm{~h}$ on $0.5 \%$ aqueous agarose. Thereafter, they were allowed to feed on standard food for $15 \mathrm{~min}$, and were transferred onto 1\% indigo (Sigma-Aldrich, \#229296) colored food for $15 \mathrm{~min}$. The flies were observed under a light microscope and scored for crop and gut color. Flies that consumed indigo blue food had blue abdomens, whereas those that did not feed on the blue food after the transfer had white abdomens. Preliminary experiments were conducted where the flies' first meal was dyed with $1 \%$ carmine red (Sigma-Aldrich), to visualize that the flies fed on the first meal. For the final scoring however, white and indigo blue food was used in order to more accurately score the flies. In all experiments on adult Drosophila only male flies were utilized and we report on the amount of blue dye ingested.

\section{ABSORBANCE MEASURE FOR OUANTIFICATION OF INGESTED FOOD}

To quantify the food intake of the flies more accurately; the absorbance of the ingested dye was measured as previously described (Edgecomb et al., 1994; Meunier et al., 2007). Flies in groups of 20 were starved for 1 day on $0.5 \%$ agarose. The flies were transferred into vials containing $1 \%$ sucrose in $1 \%$ agarose. After $20 \mathrm{~min}$, the flies were again transferred into new vials containing $1 \%$ sucrose in $1 \%$ agarose, but with $1 \%$ indigo dye (Sigma-Aldrich), and left to feed for another $15 \mathrm{~min}$. The tested flies were homogenized with a mortar in PBS and centrifuged for $3 \mathrm{~min}$. The supernatant was treated with $n$-heptane to remove lipid debris and the absorbance of the dye was measured in a Jenyway Genova spectrophotometer at $620 \mathrm{~nm}$.

\section{LARVAL FOOD CHOICE TEST}

Feeding third instar larvae (96-h-old) were collected and placed in Petri dishes, $15 \mathrm{~cm}$ in diameter. These Petri dishes had previously been prepared with an inner circle of sugar-free medium or medium with $2 \%$ caffeine, whereas the outer circle was made from standard food. The larvae were allowed to feed at libitum for $15 \mathrm{~min}$ and thereafter the larvae present in the two different circles were counted.

\section{ADULT FOOD CHOICE TEST}

The adult food choice test was adapted from Ribeiro and Dickson (2010) and Al-Anzi et al. (2010). A 96-well plate was filled alternately in a checkerboard pattern with food with our without caffeine (or without sugar in separate tests). The caffeine-spiked (or sugar-free) food was dyed with blue dye. The sedated flies were placed in the blue non-desirable food but were allowed to walk out of the well to choose another food well (they could not fly due to a cover). After feeding, the flies' abdomens were visually inspected under a microscope and scored for gut coloring. The assay was performed with the caffeine-spiked (or sugar-free) food being either dyed or undyed in order to eliminate possible effects of the dye (i.e., reversing the color coding of the food). In each test we used a minimum of 300 flies of each genotype. A test was repeated four times with 60-110 flies in each replicate.

\section{STARVATION ASSAY}

To investigate the role of DSK and DILPs in starvation resistance, flies were subjected to starvation according to the protocol of Lee and Park (2004). Male flies, aged 4-8 days, were anesthetized using $\mathrm{CO}_{2}$ and placed individually in $2 \mathrm{ml}$ glass vials containing $0.5 \%$ aqueous agarose kept at $25^{\circ} \mathrm{C}$. This provided them with water but no food. Dead flies were counted every $12 \mathrm{~h}$ and the resulting survival curve was analyzed with Log-rank test (Mantel-Cox) in Prism GraphPad 5.0.

\section{RNA EXTRACTIONS AND QUANTITATIVE REAL TIME PCR}

Total RNA from whole heads was extracted by using TRIzol (GIBCO) according to the manufacturer's protocol. The RNA was treated with DNase to remove any residual genomic DNA (Turbo DNA-freeTM, Ambion). Treated mRNA was reverse transcribed to cDNA using Quantitect Reverse Transcription Kit (Qiagen) according to the manufacturer's instructions. The dilp primers were as follows: dilp $2 \mathrm{~F}$ 
(forward), TCTGCAGTGAAAAGCTCAACGA; dilp2R (reverse), TCGGCACCGGGCATG; dilp3F, AGAGAACTTTGGACCCCGTGAA; dilp3R, TGAACCGAACTATCACTCAACAGTCT; dilp5F, GAGGCACCTTGGGCCTATTC; and dilp5R, CATGTGGTGAGATTCGGAGCTA. The $d s k$ primers used were: $d s k$ (forward) CCGATCCCAGCGCAGACGAC and $d s k$ (reverse) TGGCACTCTGCGACCGAAGC.

PCR was performed using Taqman Universal PCR Master Mix according to the manufacturer's instructions (Applied Biosystems), with the exception that $25 \mu \mathrm{l}$ reaction volumes were used, on an ABI Prism 7000 (Applied Biosystems). Endogenous genetic control ( $r p 49$ ) primers were as follows: $r p 49 \mathrm{~F}$, CACACCAAATCTTACAAAATGTGTGA; and rp49R, AATCCGGCCTTGCACATG.

All samples were analyzed in triplicates, and the measured concentration of mRNA was normalized relative to endogenous rp49 control values. Experiments were made in three replicates starting from new RNA extraction. The relative levels of a given mRNA were quantified from the normalized data according to the $\Delta \mathrm{Ct}$ analysis (Livak and Schmittgen, 2001).

\section{STATISTICS}

All experiments were run at least in triplicate with a minimum of 40 flies of each genotype in each replicate. Statistics were performed using GraphPad Prism 5.0. The starvation and oxidative stress survival results were analyzed with Log-rank test (MantelCox) and the food intake assay results were analyzed with one-way ANOVA and Tukey post hoc test. The quantitative real time PCR (qPCR) results were analyzed with one-way and two-way ANOVA.

\section{RESULTS}

\section{DSK AND DILPS CO-LOCALIZE IN THE INSULIN-PRODUCING CELLS}

A subset of the median secretory cells of the protocerebrum produces DILP2, 3, and 5. These cells, designated IPCs have axon terminations in the corpora cardiaca, the aorta, the crop, and the anterior midgut, all presumed to be neurohemal release sites for circulating hormones (Cao and Brown, 2001; Rulifson et al., 2002; Cognigni et al., 2011). The presumed dendrites of the IPCs are located in the pars intercerebralis, dorsally in the protocerebrum.

To visualize neuronal $D s k$ expression we used a $D s k$-Gal4 line (Park et al., 2008) to drive UAS-mCD8-GFP. We found Dsk-Gal4 expression in several neuron groups in the adult brain, including cells resembling the IPCs (Figures 1A1,B1). Using anti-DSK antiserum, we labeled similar neurons in the brain (Figures 1A2,B2). In addition, we found DSK-immunolabeling and Gal4 expression in interneurons in other parts of the protocerebrum and subesophageal ganglion (Figure 1A2), also shown by Nichols et al. (Nichols and Lim, 1996; Nichols et al., 1997a,b). Since we found DSK immunoreactivity and Dsk-Gal4 expression in several cells among the median secretory cells, probably including the IPCs, we applied DILP2 antiserum to adult brains for identification. Thus, we confirmed that the Dsk-GFP-expressing median secretory cells also are DILP immunopositive (Figures 1B1-B3) and conversely we showed that most of the Dilp2-Gal4-expressing IPCs react with antiserum to DSK (Figures 1C1-C3). Also in the third instar larvae many of the IPCs co-express DSK immunoreactivity (Figures 1D1-D3) as previously shown (Park et al., 2008). Not all IPCs express DSK in flies or larvae and the DSK expression is somewhat variable.

Since most of the IPCs in the adult brain also express DSKs, it is suggestive that these cells signal with both DILPs and DSKs. Since the IPCs are neurosecretory cells we expect that the DSKs are released from these cells as circulating hormones. Hence, we went on to investigate the functional role of DSKs in the IPCs.

\section{FOOD INTAKE IS REGULATED BY DSKs IN THE IPCs}

The co-localization of DILPs and DSKs in the IPCs suggests that the hormonal actions of the two sets of peptides may be functionally coordinated. DSKs have previously been proposed to be satiety signals in blowflies and other insects (Maestro et al., 2001; Wu et al., 2003; Downer et al., 2007; Meyering-Vos and Muller, 2007; Nichols et al., 2008) and silencing of IPCs has been shown to affect feeding in Drosophila (Broughton et al., 2010; Cognigni et al., 2011). We set out to determine the function of the DSK signaling from the IPCs as compared to signaling from the entire population of DPCs. More specifically we ask whether the DSKs produced in the IPCs are sufficient to regulate feeding and satiety? In all experiments on adult Drosophila only male flies were utilized.

In the following experiments flies were starved for $18 \mathrm{~h}$ ahead of the experiment and were subsequently placed on standard food for $15 \mathrm{~min}$ before transferred to indigo colored food. This duration was chosen since a normal meal lasts about $15 \mathrm{~min}$ (Al-Anzi et al., 2010).

To investigate effect of DSK-knockdown in feeding, Dsk-RNAi was driven both in IPCs (with Dilp2-Gal4) and in DPCs (with Dsk-Gal4). Driving Dsk-RNAi in either cell population rendered the same phenotype: nearly $100 \%$ of the flies with diminished Dsk-levels continued to feed on the indigo colored food after transfer, whereas only approximately $70 \%$ of the controls did ( $p<0.001$ for both genotypes, One-way ANOVA; Figure 2). Control flies apparently became satiated from the first meal and did not feed on the blue food to the same extent as the test flies. The Dsk deficient flies however, displayed a defect in regulation of food intake as they continued to feed on the blue food. These experiments show that Dsk-RNAi in the IPCs is sufficient to induce a defective feeding phenotype and no additional effect was detected after knocking down Dsk in all of the DPCs.

For a more precise quantification of the food intake we measured the absorbance of the ingested dye (Meunier et al., 2007). We detected a significantly higher absorbance in the Dilp2-Gal4/DskRNAi and Dsk-Gal4-Dsk-RNAi flies than in controls $(p<0.001$ for each genotype, One-way ANOVA; Figure 3A). These results further support that diminishment of DSKs in the IPC is sufficient to cause the observed orexogenic phenotype.

A feeding test was also carried out in larvae to examine the effects of DSK manipulation on feeding behavior in earlier developmental stages. The third instar larvae normally feed continuously and using dyed food enabled us to obtain a measure of the amount of ingested food over time. The Dsk-RNAi larvae ingested more food than controls, both when the construct was driven in IPCs and in the DPCs; they displayed approximately 20\% higher food dye absorbance $(p<0,001$, for both genotypes compared to 

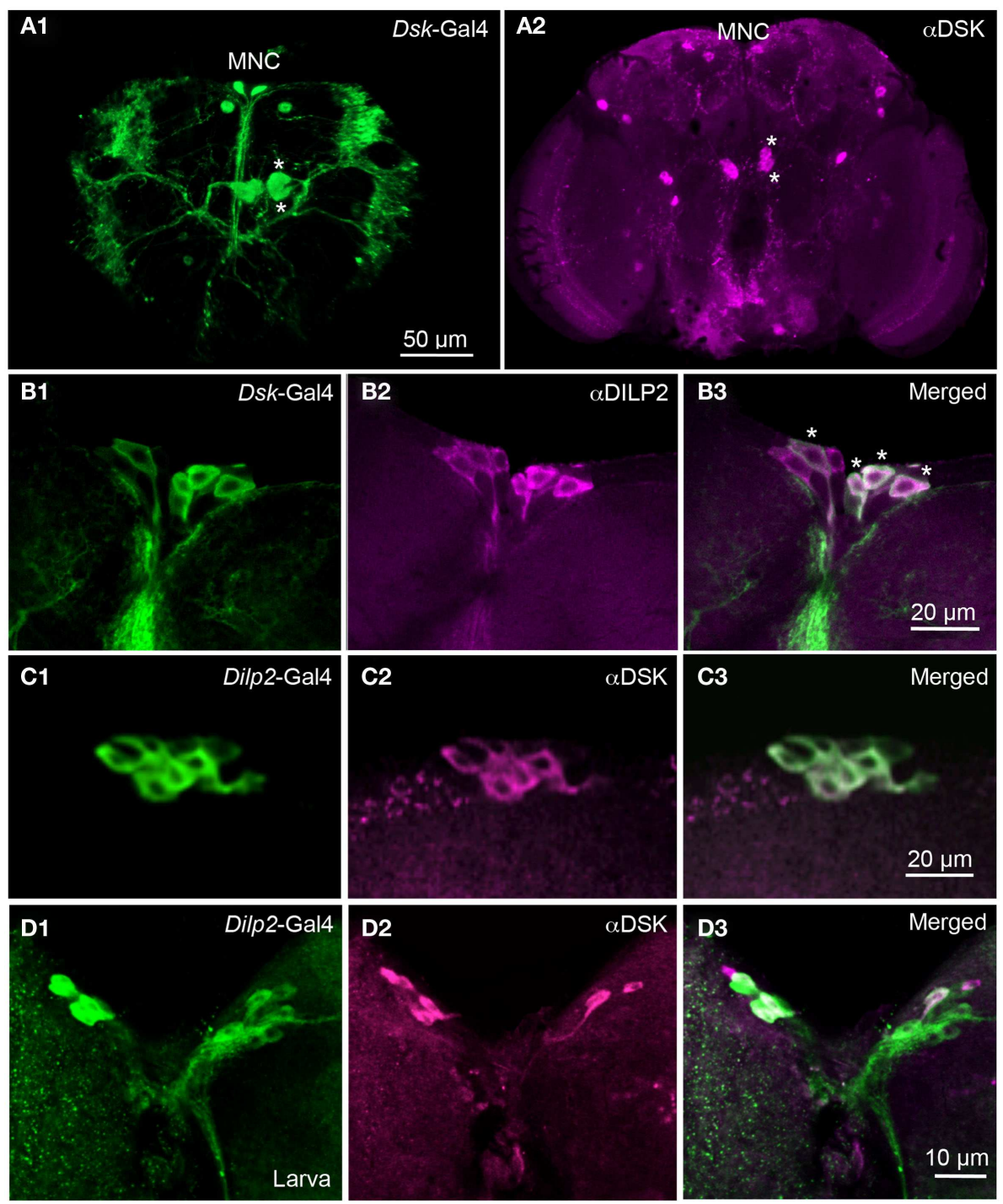

FIGURE 1 | Dilp2-expressing IPCs also display DSK immunoreactivity. (A1) Dsk-Gal4 driven GFP reveals expression in median neurosecretory cells (MNC) in the pars intercerebralis of the adult brain. Two additional larger neurons can be noted in the superior protocerebrum. Four large cells, two in each hemisphere (asterisks) of the midbrain extend arborizations toward the lateral horn, and the lateral protocerebrum. (A2) Labeling with DSK antiserum in the adult brain reveals immunoreactivity in the MNCs and in other cells in the protocerebrum. Two cells marked with asterisks correspond to the cells marked in (A1). Arborizations can be seen in the pars intercerebralis and in the subesophageal ganglion and descending to the ventral nerve cord (B1-B3). The adult IPCs co-localize Dsk-Gal4 expression (green) and DILP2 immunoreactivity (magenta). Cells with co-localized markers are indicated by asterisks (C1-C3)

Co-localization of Dilp2-Gal4-driven GFP and DSK-immunolabel in IPCs of the adult fly. The majority of the GFP expressing IPCs also display DSK immunoreactivity (D1-D3). In the larval brain the IPCs are double-labeled with antiserum to DSK and Dilp2-Gal4-driven GFP. The markers co-localize in the majority of the IPCs, but with stronger DSK labeling in some cells. In these images the intensity of mCD8-GFP fluorescence was improved by using antiserum to GFP or CD8. controls, One-way ANOVA; Figure 3B). Again, this suggests that depleting DSKs only from the IPCs is sufficient to cause a deregulation of feeding and cause an increased food intake. Thus, DSKs seem to function as a satiety signal both in larvae and in adults.

\section{FLIES DEFICIENT IN DSKs DISPLAY DEREGULATED FOOD CHOICE BEHAVIOR}

Since we could detect a defect in regulation of food intake in DSK deficient flies, we were also interested in whether DSKs play a role in food preference of the flies. Studies have previously linked deregulated food intake with aberrant food choice behavior. Flies that were made deficient in NPF, or its receptor, did not display a normal behavior in the choice between standard or distasteful (noxious) or inaccessible more solid food (Wu et al., 2005a,b; Lingo et al., 2007).

Adult flies were subjected to a food choice assay where they were exposed both to food that they normally avoid and to standard food (as detailed in material and methods). The distasteful food 
presented was either bitter due to caffeine, or was sugar-free, thus making it less palatable than the standard food. The non-palatable foods were colored blue and standard food was uncolored. Flies were placed on colored non-palatable food and given the choice

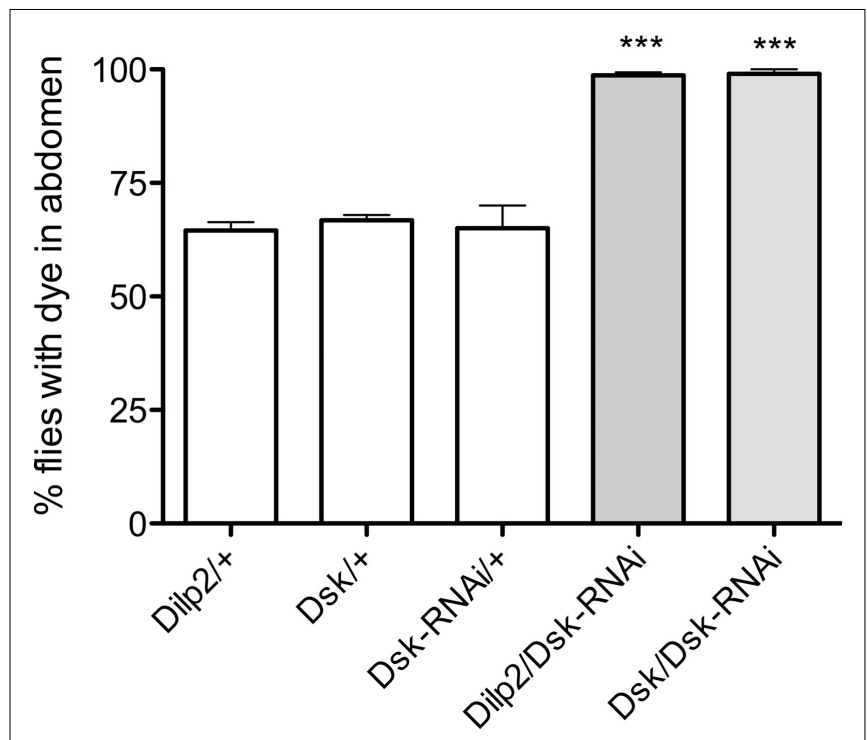

FIGURE 2 | Drosulfakinin deficient flies consume more food than controls. Ingested indigo dyed food was visually detected in the abdomen of transgene flies. In all experiments in this and other figures parental controls were crossed to wildtype $w^{1118}$ flies (reported as, e.g., Dilp2/+). After 15 min of feeding, an average of $98.6 \%$ of the flies with Dsk-knockdown in all DSK-expressing cells, DPCs (Dsk/Dsk-RNAi) and 99\% of the flies with Dsk-RNAi in IPCs (Dilp2/Dsk-RNAi) had fed on blue food, compared to only 64.5 and $66.7 \%$ of respective controls, Dilp2/+, Dsk/+, and Dsk-RNAi/+ ( $p<0.001, n=90-112$ for the different genotypes, One-way ANOVA). All experiments were performed in three replicates, $* * * p<0.001$. to remain feeding on this, or to walk to an adjacent well with standard food. The number of flies that had fed on one or the other of the food types was scored by monitoring ingested color. We observed that flies that expressed Dsk-RNAi in either the IPCs or the DPCs were significantly more likely to feed on undesirable food (caffeine-spiked or sugar-free), whereas the control flies fed more on the standard food ( $p<0.001$, One-way ANOVA; Figures 4A,B). Our data suggest that DSK deficient flies remain feeding on nonpreferred food, likely as a function of being hungry in absence of a satiety signal, and that Dsk-knockdown in IPCs is sufficient for this phenotype.

Next we inactivated neurons of interest with a constitutively active potassium channel, dOrk1 (Nitabach et al., 2002), which hyperpolarizes the neuronal membranes. We expressed dOrk1 in either IPCs or DPCs. This hyperpolarization resulted in the same phenotype as when we diminished Dsk through RNAi. The flies consumed more food that was sugar-free or spiked with caffeine than control flies did (Figures 4C,D; $p<0,001$ for all crosses and food types compared to respective controls, except $p<0,01$ for Dilp2/dOrk1 in the sugar-free food, One-way ANOVA, Tukey post test).

Furthermore, we examined larval food choice behavior after DSK manipulation. Third instar larvae were given the choice between standard food and sugar-free food or caffeine-spiked food. The larvae were placed on the non-desirable food (of either type) surrounded by standard food and allowed to feed for $15 \mathrm{~min}$. The percentage of larvae that stayed in the non-desirable food rather than moving into the standard food was determined. Control larvae moved away from the caffeine-spiked or sugar-free food and moved into the standard food and about $97 \%$ of them were found in this area at the end of the experiment (Figures 5A,B). When Dsk-RNAi was driven with Dilp2-Gal4 or Dsk-Gal4, the larvae stayed in the non-desirable food to a larger extent than control larvae ( $p<0.001$ for both Dsk/Dsk-RNAi and Dilp2/DskRNAi compared to parental controls). It can be remarked that
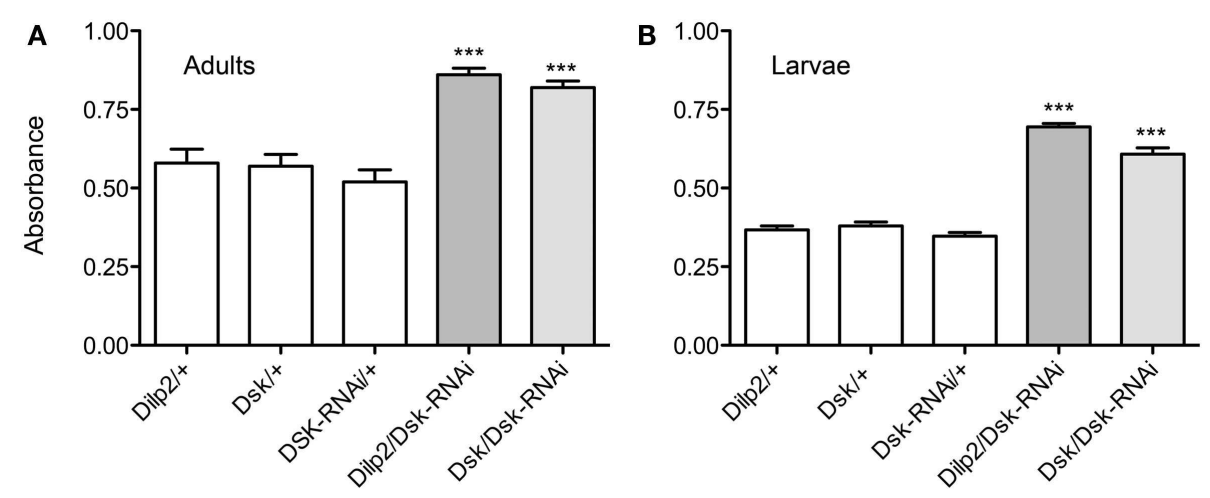

FIGURE 3 | Diminishing Dsk causes adult flies and larvae to ingest more food. For quantification of food intake the absorbance of the ingested food dye in flies and larvae was measured at $625 \mathrm{~nm}$ by spectrophotometry. The absorbance of ingested colored food was measured in 20 adult flies or larvae of each genotype, and the experiments were repeated four times $\left({ }^{* *} p<0.001\right)$. (A) The absorbance of ingested colored food was measured in adult flies after $15 \mathrm{~min}$ of feeding. The mean absorbance was $43 \%$ higher in Dsk-Gal4/Dsk-RNAi flies and $43 \%$ higher in Dilp2/Dsk-RNAi flies than in respective controls,
Dilp2/+, Dsk/+, and Dsk-RNAi/+ ( $p<0.001$, One-way ANOVA), indicating a larger food intake amongst the flies with DSK-knockdown both in all DPCs and only in IPCs. (B) DSK regulates food intake also in larvae. After $15 \mathrm{~min}$ of feeding, a mean absorbance of 0.60 in Dsk-Gal4/Dsk-RNAi and 0.695 in Dilp2/Dsk-RNAi larvae was measured compared with $0.35,0.37$, and 0.38 in controls ( $p<0.001$, One-way ANOVA). The Dsk/Dsk-RNAi and Dilp2/Dsk-RNAi larvae displayed an almost 50\% higher absorbance than controls. For all experiments manipulations the IPCs alone were sufficient to induce a feeding phenotype. 


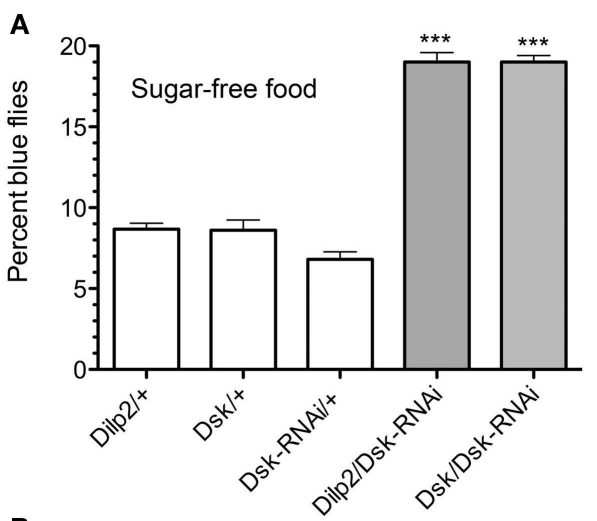

B

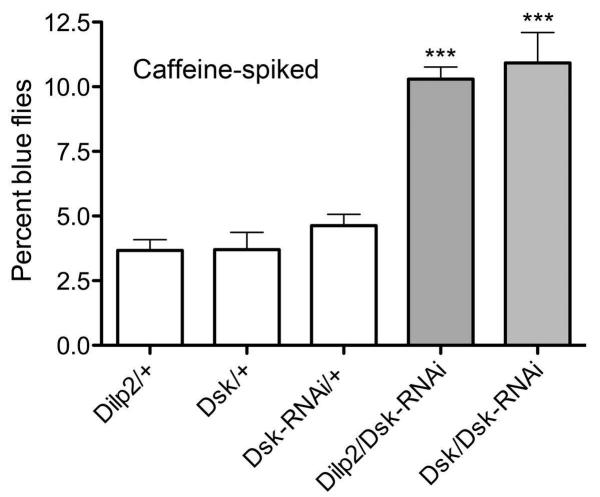

C

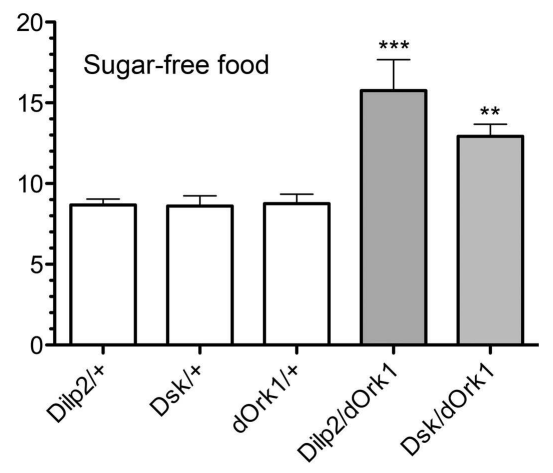

D

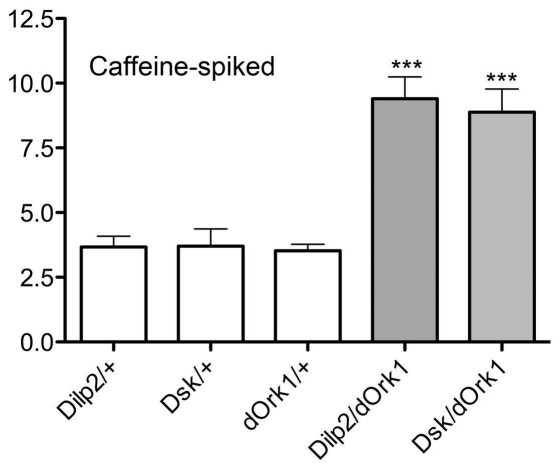

FIGURE 4 | Drosulfakinin affects food quality discrimination. Ten adult male flies of each genotype were used in each test, and the test was repeated five times $\left({ }^{*} p<0.01,{ }^{* *} p<0.001\right.$, One-way ANOVA, Tukey post test). Adult male flies were allowed to choose between caffeine-spiked, sugar-free, and standard fly food as described in "Materials and Methods." The standard food was white and the two non-preferred foods with blue dye. Flies were put in wells with non-preferred food and allowed choice to feed or move to an adjacent well with standard food. Between 60 and 110 flies of each genotype were used in each test and each test was repeated four times $\left({ }^{* *} p<0.01,{ }^{* *} p<0.001\right.$, One-way ANOVA, Tukey post test). Each set of experiments was also run with the coloring of the food reversed (i.e., blue standard food) with similar results (not shown). This figure shows when the larvae were subjected to sugar-free food (Figure 5A), the percentage of control larvae that stayed in that food was larger compared to when they were subjected to caffeine.

In summary, when the flies or larvae have reduced levels of DSK in the IPCs or in the DPCs, or these cells are inactivated, they more readily accept to feed on caffeine-spiked or sugar-free food compared to controls. DSK-knockdown seems to modify the flies' food preferences, rendering them less choosy, probably as an effect of lack of a satiety signal. Furthermore, DSK signaling from the IPCs seems to be sufficient to mediate this effect.

\section{QUANTIFICATION OF DSK AND DILP TRANSCRIPTS AFTER INTERFERENCE WITH IPCs AND DPCs}

Since DSK appears to be a hormonal satiety signal that affects feeding behavior in Drosophila, it is possible that the levels of Dsk/DSK affect the Dilp/DILP levels via feedback regulation. We therefore performed qPCR to measure the transcript levels of the different Dilps after manipulation of the Dsk-levels.

The levels of Dilp transcripts have been shown to be differentially affected when flies were subjected to different diets or other manipulations of IPC activity (Hwangbo et al., 2004; Broughton et al., 2008, 2010; Buch et al., 2008; Min et al., 2008; Karpac et al., 2009; Grönke et al., 2010; Slack et al., 2010; Birse et al., 2011). We analyzed Dilp transcript levels in fly brains in response to Dskdepletion in IPCs or DPCs to determine if Dsk-levels have an effect on Dilp levels in fed or starved flies. Analysis by qPCR showed that the levels of Dilp2, 3, and 5 increase when Dsk is knocked down in either IPCs or DPCs in flies that are fed ad libitum ( $p<0.001$ for all three Dilps, One-way ANOVA, Tukey post test; Figures 6A-C). In flies exposed to $24 \mathrm{~h}$ starvation, the Dilp2, 3, and 5 levels decrease in both Dsk-knockdown flies and all controls $(p<0.01$, One-way ANOVA; Figures 6A-C). Note that the Dilp2 levels in flies starved for 24 after Dsk-knockdown are not significantly different from 

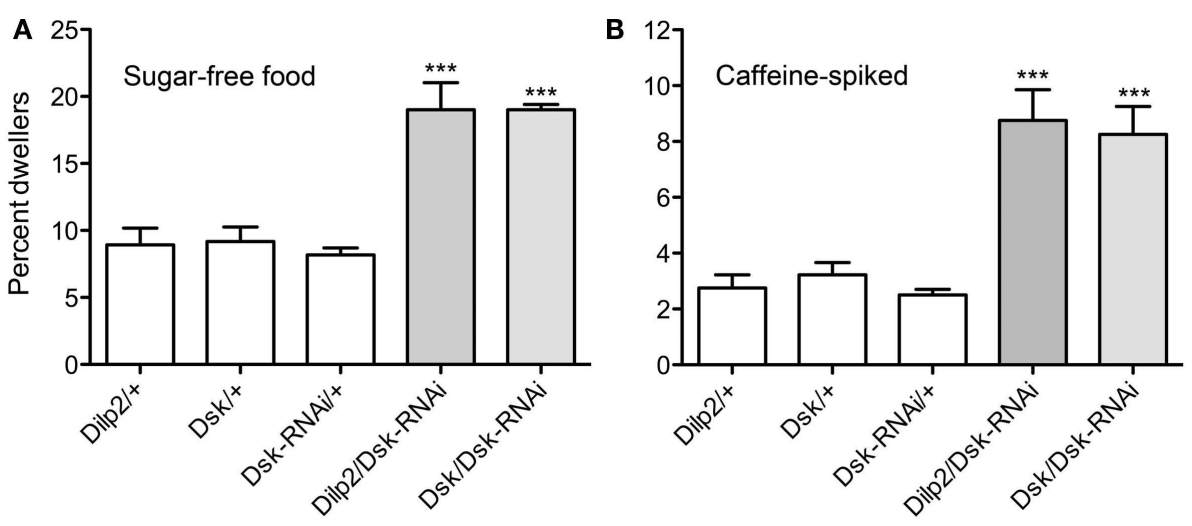

FIGURE 5 | Drosulfakinins affect larval food choice behavior. Twenty larvae of each genotype were placed in Petri dishes and allowed to choose between caffeine-spiked food and standard food. The experiment was repeated four times $\left({ }^{*} p<0.01,{ }^{* * *} p<0.001\right.$, One-Way ANOVA, Tukey post test). (A) Test on sugar-free food. Dsk-knockdown by RNAi in IPCs (Dilp2/DSK-RNAi) or DPCs (Dsk/Dsk-RNAi) resulted in larvae that remained in the sugar-free food to a higher extent than controls (white bars). Results are given as percent dwellers, i.e., larvae remaining in non-preferred food. (B) Test of same genotypes on caffeine-spiked food. Again, knockdown of Dsk in either IPCs or DPCs resulted in larvae that were more likely to dwell in the caffeine-spiked rather than moving to the standard food. those seen in starved controls (n.s., Two-way ANOVA). Diminution of Dsk thus affects Dilp transcripts only in normally fed flies where the levels of Dilp2, 3, and 5 increase to about 1.5- to 2fold the levels seen in the controls. Interestingly, it is sufficient to knockdown Dsk in IPCs to obtain an increase in Dilp levels.

Since the IPCs express Dilp2, 3, and 5 we utilized a Dilp2,3,5 mutant (Grönke et al., 2010) to knockdown insulin levels in the IPCs and measured the levels of Dsk transcript in fed and starved flies. In addition, we tested the effects of Dilp5-RNAi in IPCs on Dsk transcription levels. The Dilp5-RNAi was chosen because Dilp5 levels were shown to be sensitive to starvation in this and other reports (Broughton et al., 2008; Min et al., 2008). Normally fed flies with mutated Dilp2,3,5 display lower levels of Dsk than controls (Figure 7; $p<0.001$, One-way ANOVA). After $24 \mathrm{~h}$ starvation, the levels of Dsk transcript decreased in all genotypes tested, including controls (Figure 7). This is as predicted since there is no need for a satiety signal during starvation. Knocking down Dilp5 only in the IPCs did not significantly alter Dsk-levels in fed or starved flies compared to controls (n.s., One-way ANOVA, Tukey post test; Figure 7).

Taken together, the qPCR analysis above suggests a correlation between the Dilp levels and the Dsk-levels. The Dilp levels increase in Dsk deficient flies and Dsk transcript levels diminish in Dilp2,3,5 deficient flies. A possible explanation for these results is a feedback where DSKs act on the IPCs either directly or via other cells to regulate Dilp transcription. Probably the increased Dilp levels in fed flies with reduced Dsk (and diminished satiety signaling) are caused by increased food intake leading to a demand for higher levels of circulating DILPs to reallocate carbohydrates. Furthermore, it is sufficient to diminish Dsk in IPCs to obtain an effect on Dilp levels. Similarly, the DILPs are likely to regulate Dsk transcription directly or indirectly via signaling from the fat body.

\section{RESISTANCE TO STARVATION}

It is known that decreased DILP signaling leads to increased resistance to starvation and we wanted to determine whether altering the Dsk-levels affects survival in food deprived flies. We thus tested survival of $D s k$-RNAi flies exposed to starvation by feeding aqueous agarose.

When the flies were deficient in Dsk, either by driving DskRNAi in IPCs or DPCs (Figure 8) they displayed longer life spans at starvation than controls $(p<0.001$ for both genotypes compared to controls, Log-rank test). It was shown earlier that partial ablation of the IPCs by expressing UAS-rpr produced the same phenotype (Broughton et al., 2005). However, the finding that Dsk-knockdown by RNAi in the IPCs (and DPCs) extends life span at starvation is a novel finding. This suggests that IPCs influence resistance to starvation not only by release of DILPs, but that also DSKs may have an impact on this resistance. Alternatively, the extension of life span is caused by the DSK-depleted flies feeding more vigorously before the start of the starvation experiment and therefore having larger energy stores.

\section{DISCUSSION}

Not only the structural resemblance between insect sulfakinins and mammalian CCK and their receptors is striking, but also the finding that sulfakinins act as satiety signals in both groups (Nichols et al., 1988; Wei et al., 2000; Maestro et al., 2001; Kubiak et al., 2002; Wu et al., 2003; Downer et al., 2007; Dockray, 2009). We show here that the Drosophila sulfakinins, DSKs, are important in regulating food intake and more specifically that DSKs in a set of brain neurosecretory cells (IPCs) that also produce insulin are sufficient for signaling satiety. Other studies made in locust, cricket, cockroach, and blowfly have employed various techniques to demonstrate that sulfakinins regulate feeding and satiety (Wei et al., 2000; Maestro et al., 2001; Downer et al., 2007; Meyering-Vos and Muller, 2007). For instance in the blowfly, Phormia regina, injected sulfakinins induce satiety for carbohydrate but not protein intake (Downer et al., 2007). We used targeted genetic interference with Dsk-levels or membrane activity in the specific neurons producing DSKs, the DPCs, and tested the effects on several aspects of feeding. Flies with diminished Dsk or activity in DPCs feed more vigorously 


\section{A}

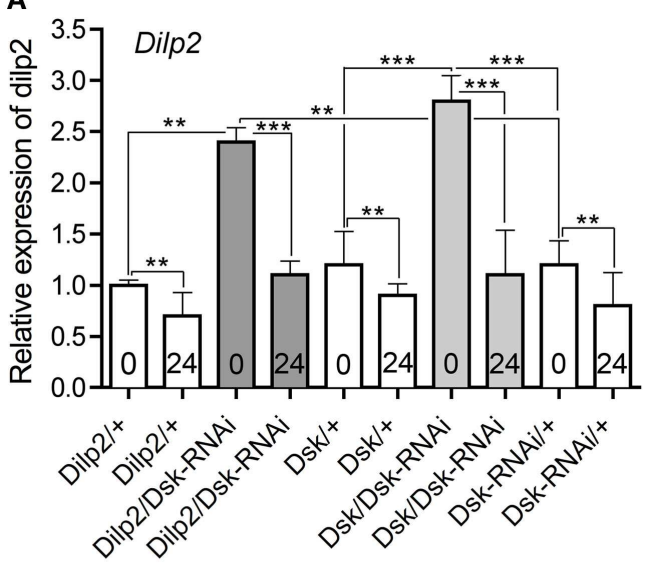

B
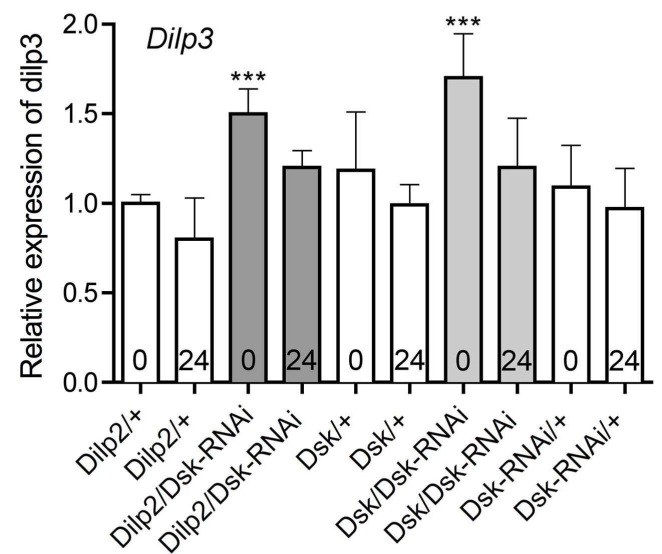

C

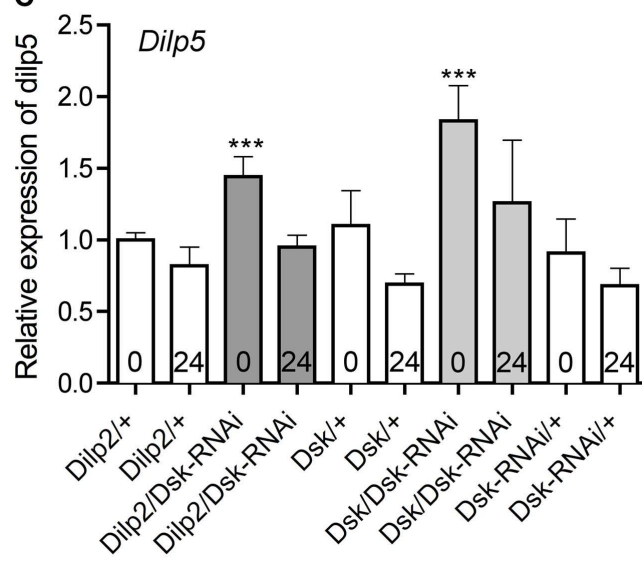

FIGURE 6 | Relative expression levels of Dilp transcripts in DSK deficient files. The effect of Dsk-knockdown in the IPCs (Dilp2/Dsk-RNAi; dark gray bars) and DPCs Dsk/Dsk-RNAi (light gray bars) on Dilp expression in the brain of adult flies was measured by quantitative real time PCR. Fed flies (bars indicated with 0 ) and flies starved for $24 \mathrm{~h}$ (bars indicated with 24) were monitored. Control flies (Dilp2/+, Dsk/+, and Dsk-RNAi/+) are shown in white bars. Data are shown as mean relative expression \pm SD $(n=10$ for each genotype; each genotype was assayed in triplicate, experiments in triplicate), asterisks denote significant difference compared to controls for fed flies only $\left.{ }^{* *} p<0.01,{ }^{* * *} p<0.001\right)$, except in (A) where all significance comparisons are shown. Note that the levels of Dilp2, 3, and 5 diminish significantly in all genotypes after $24 \mathrm{~h}$ starvation $(p<0.01$, One-way

(Continued)

\section{FIGURE 6 | Continued}

ANOVA, Bonferroni's post hoc test); this is only indicated for Dilp2 in (A). (A) The relative levels of Dilp2 transcript increase in Dsk-knockdown flies compared to parental controls (white bars) in fed flies ( $p<0.001$, One-way ANOVA). Depletion of DSK, either in IPCs or in the DPCs (Dilp2/Dsk-RNAi and Dsk/Dsk-RNAi) increased Dilp2 transcripts in fed flies. The levels of Dilp2 are significantly lower after $24 \mathrm{~h}$ starvation for all genotypes (**for all controls and ***for the two sets of Dsk-RNAi flies). Note that the Dilp2 transcript levels in starved (24) experimental flies (Dilp2/Dsk-RNAi and Dsk/Dsk-RNAi) do not differ significantly from those of starved controls (white bars; n.s., One-way ANOVA), not indicated in figure. (B) Dilp3 transcript levels are higher in fed flies (0) that express Dsk-RNAi in IPCs and DPCs (gray bars) than in fed controls (white bars; $p<0.001$, One-way ANOVA). Like in (A) all genotypes display significantly lower Dilp levels after $24 \mathrm{~h}$ starvation (not indicated in Figure). (C) Dilp5 transcript levels also increased significantly in fed Dsk deficient flies (Dilp2/Dsk-RNAi and Dsk/Dsk-RNAi) compared to controls ( $p<0.001$, One-way ANOVA). Like in (A) all genotypes display significantly lower Dilp levels after $24 \mathrm{~h}$ starvation (not indicated in Figure).

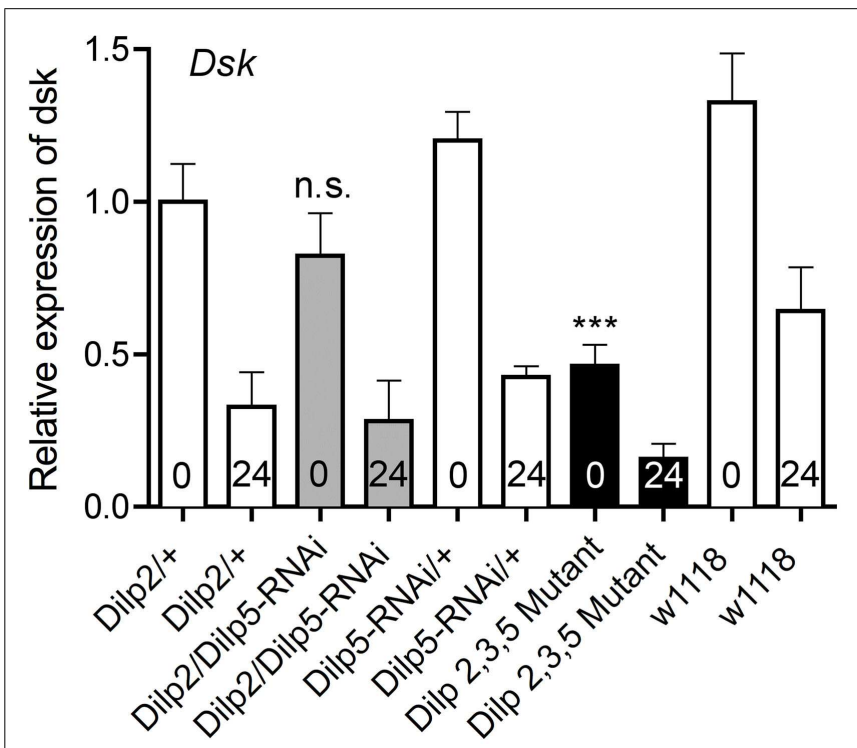

FIGURE 7 | Relative expression levels of Dsk transcripts in Dilp

deficient files. The Dsk transcript levels decreased significantly in normally fed Dilp2,3,5 mutants (black bar) compared to controls (white bars;

${ }^{* * *} p<0,001$, One-way ANOVA, $n=10$ for each genotype, assays run in triplicate, experiments in triplicate). Even though Dsk-levels drop significantly in all genotypes tested during starvation $(p<0,001$, One-way ANOVA), the levels of Dsk mRNA after $24 \mathrm{~h}$ of starvation are lower in Dilp2,3,5 mutants (black bar, 24) than in controls (white bars $24 ; p<0,01$, One-way ANOVA). Silencing only Dilp5 in the IPCs with RNAi

(Dilp2/Dilp5-RNAi; gray bars) did not affect Dsk transcript levels under normal fed conditions, nor is the drop in Dsk-levels significantly different from that seen in controls during starvation (n.s, Two-way ANOVA).

than controls and are less selective in food quality. Most interestingly, it is sufficient to diminish DSK signaling from the IPCs to affect feeding. Our experiments suggest that the DILPs and DSKs released from the IPCs act in concert to regulate feeding and metabolism and also that the peptides display mutual feedback regulation of peptide gene transcription in these cells. 


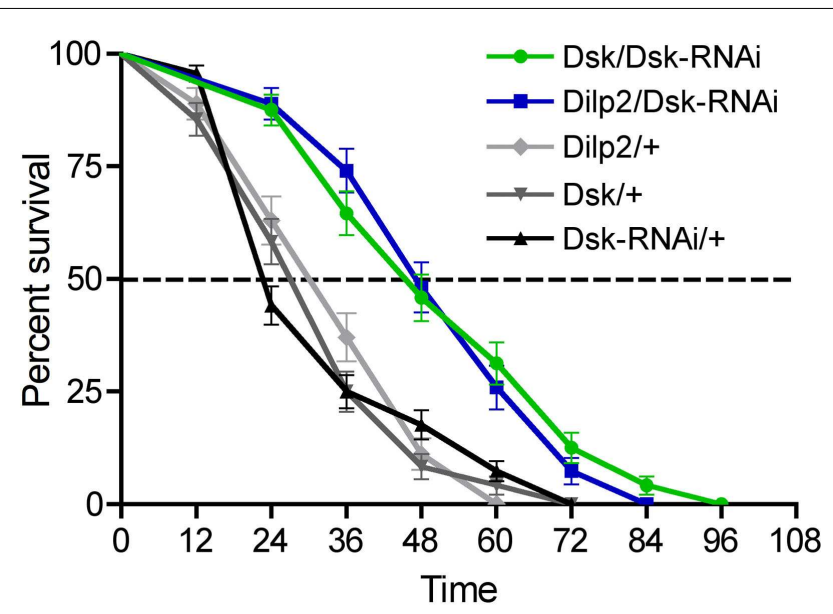

FIGURE 8 | Drosulfakinin and Drosophila insulin-like peptide deficient flies are more resistant to starvation. We tested the effect of Dsk-knockdown in the IPCs (Dilp2-Gal4/Dsk-RNAi) and DPCs Dsk/Dsk-RNAi on survival at starvation. Using both Gal4 lines we obtained an extension of life span of the starved flies $(p<0.01$ and $p<0.001$, $n=70-95$ for each genotype, run in triplicate, Log-rank test), compared to the controls Dilp2/+, Dsk/+, and Dsk-RNAi/+. The extension of lifespan seen here could be caused by the DSK and DILP deficient flies feeding more prior to the starvation experiment and thus having larger energy stores.

While co-localization of DSK and DILPs in brain IPCs was already known in Drosophila larvae (Park et al., 2008), we show here that the peptides are also co-localized in IPCs of the adult fruitfly. Most, but not all, of the IPCs produce DSKs at both developmental stages. It is not clear what the targets of DSK released from the IPCs are. Central neurons of the brain that regulate feeding is one possibility; peripheral targets associated with the alimentary canal or feeding apparatus is another. The cellular expression of the two DSK receptors (CG6857 and CG6881; Kubiak et al., 2002) is not known and consultation of the FlyAtlas ${ }^{1}$ (Chintapalli et al., 2007) and FlyBase ${ }^{2}$ reveals very low transcript levels for both receptors, with the highest for CG6857 in the brain, salivary gland, and fat body. Interestingly, the crop, crop duct, the proventriculus, and anterior midgut are supplied by axon terminations from the IPCs (Cao and Brown, 2001; Cognigni et al., 2011) and thus these could be targeted by DSKs. It may be that muscle contractions are regulated by DSK released directly onto these parts of the intestine, similar to CCK in mammals (Liddle et al., 1986; Dockray, 2009; Moran and Dailey, 2009). It is known that sulfakinins stimulate muscle contractions in insects (Nachman et al., 1986a; Melcher and Pankratz, 2005), but no specific action on the crop and proventriculus has been demonstrated (see Downer et al., 2007). However the peptide DSK-0 that is also encoded on the Dsk gene of Drosophila has been shown to induce contractions in the crop when applied at higher concentrations, indicative of non-hormonal action (Palmer et al., 2007).

\footnotetext{
${ }^{1}$ http://www.flyatlas.org/
}

2http://flybase.org/
The sequence of DSK- 0 is very different from DSK-1 and 2, and the peptide not likely to activate the two known DSK receptors.

Drosulfakinins are expressed in the IPCs, as well as other cells in the adult brain such as four large median posterior cells and some smaller cells in the protocerebrum and a few in the subesophageal ganglion (see also Nichols and Lim, 1996; Nichols et al., 1997a). Thus the Dsk-Gal4 driver that identifies all the DPCs includes the IPCs. By using a driver uniquely expressed in the IPCs (Dilp2Gal4), we could distinguish the role of DSKs in the IPCs from that of global DSKs by expressing Dsk-RNAi. Significantly, when driving Dsk-RNAi in IPCs only, all of the phenotypes observed, including deregulated feeding, were the same as when driving Dsk-RNAi in all DPCs. This suggests that DSKs have an effect on regulation of food intake and food choice in Drosophila that indicates that the peptides signal satiety and also that the DSK released from the IPCs is sufficient for this signaling.

In our experiments, DSK does not only affect food intake, but also the food choice of larvae and flies. That the DSK deficient animals are less discriminating with food quality could depend on defective olfaction or taste, or that they are hungry enough to eat also noxious food. Nichols et al. (2008) showed that DSK has an effect on odor preference in Drosophila larvae. However, we observed the same alteration in food choice in flies with DSK reduced only in the IPCs, which probably excludes that taste or olfaction is deficient due to direct DSK modulation of these sensory systems. It is more likely that the DSK deficient flies or larvae do not receive satiety signals and thus remain in the non-preferred food and feed rather than to venture out to find another better food source. Defective food choice behavior has been seen in flies with impaired hugin and NPF signaling (Wu et al., 2003, 2005a,b; Melcher and Pankratz, 2005). In the case of NPF this altered behavior has been associated with insulin signaling; neurons expressing the NPF receptor are regulated by DILPs (Wu et al., 2005b; Lingo et al., 2007). Also the neuropeptides sNPF, leucokinin, and Allatostatin A are known to regulate food intake in Drosophila (Lee et al., 2004, 2008; Al-Anzi et al., 2010; Hergarden et al., 2012). Thus, the control of feeding behavior in Drosophila employs several peptides/peptide hormones, like in mammals (McMinn et al., 2000; Melcher et al., 2007; Moran, 2009). Our data adds DSKs to the set of different neuropeptides that regulates feeding and maybe indirectly metabolism in Drosophila.

We measured the Dsk transcript levels in flies mutant for Dilp 2, 3, and 5 and found a significant decrease in Dsk-levels under normal feeding conditions. This could either be caused by a direct feedback regulation of Dsk transcription by DILPs that is defective in the mutant, or by indirect feedback regulation via the fat body. For instance it is possible that the decreased levels of Dsk transcript observed in the Dilp 2, 3, and 5 mutant is due to a diminished ability for the fly to store energy because of the low circulating insulin levels and decreased signaling to the fat body. This might induce a perceived need for consumption of more energy, and thus a diminished need for a satiety signal, DSK. Thus the fat body may send a signal back to the brain IPCs leading to decreased Dsk transcription.

Our study shows that Dilp 2, 3, and 5 transcript levels are increased by diminishment of DSK-levels under normal feeding 
conditions. However, at starvation Dilp levels normally decrease and the Dsk-knockdown does not seem to affect this drop. This is consistent with the idea that DSK signaling does not occur during starvation as there is no need for a satiety signal. The increased Dilp levels in fed flies with reduced Dsk are probably caused by increased food intake leading to a demand for higher levels of circulating DILPs to reallocate carbohydrates.

Knockdown of different components of the insulin pathway results in an extension of life span at starvation (Clancy et al., 2001; Tatar et al., 2001; Giannakou et al., 2004; Hwangbo et al., 2004; Grandison et al., 2009; Enell et al., 2010). The increased survival observed when Dsk is knocked down indicates that DSK signaling might affect resistance to starvation, at least indirectly. However, it is possible that Dsk-knockdown flies feed more before the onset of the starvation experiment and thus have larger energy stores. It is thus not clear how DSK and DILP signaling acts in a coordinated fashion during starvation, or how DSKs might affect starvation resistance. Possibly also the DSKs act on the fat body, since at least one of the DSK receptors seem to be expressed in this tissue (reported in FlyAtlas) $)^{3}$.

${ }^{3} \mathrm{http}: / /$ www.flyatlas.org/

\section{REFERENCES}

Aguilar, R., Maestro, J. L., Vilaplana, L., Pascual, N., Piulachs, M. D., and Belles, X. (2003). Allatostatin gene expression in brain and midgut, and activity of synthetic allatostatins on feeding-related processes in the cockroach Blattella germanica. Regul. Pept. 115, 171-177.

Al-Anzi, B., Armand, E., Nagamei, P., Olszewski, M., Sapin, V., Waters, C., Zinn, K., Wyman, R. J., and Benzer, S. (2010). The leucokinin pathway and its neurons regulate meal size in Drosophila. Curr. Biol. 20, 969-978.

Antonova, Y., Arik, A. J., Moore, W., Riehle, M. R., and Brown, M. R. (2012). "Insulin-like peptides: structure, signaling, and function," in Insect Endocrinology, ed. L. I. Gilbert (New York: Elsevier/Academic Press), 63-92.

Audsley, N., and Weaver, R. J. (2009). Neuropeptides associated with the regulation of feeding in insects. Gen. Comp. Endocrinol. 162, 93-104.

Baker, K. D., and Thummel, C. S. (2007). Diabetic larvae and obese flies-emerging studies of metabolism in Drosophila. Cell Metab. 6, 257-266.

Barth, R. J. (2011). Insulin resistance, obesity and the metabolic syndrome. S. D. Med. Spec No. 22-27.

Birse, R. T., Söderberg, J. A., Luo, J., Winther, $\AA$. M., and Nässel, D. R. (2011). Regulation of insulin-producing cells in the adult Drosophila brain via the tachykinin peptide receptor DTKR. J. Exp. Biol. 214, 4201-4208.

Brogiolo, W., Stocker, H., Ikeya, T., Rintelen, F., Fernandez, R., and Hafen, E. (2001). An evolutionarily conserved function of the Drosophila insulin receptor and insulin-like peptides in growth control. Curr. Biol. 11, 213-221.

Broughton, S., Alic, N., Slack, C., Bass, T., Ikeya, T., Vinti, G., Tommasi, A. M., Driege, Y., Hafen, E., and Partridge, L. (2008). Reduction of DILP2 in Drosophila triages a metabolic phenotype from lifespan revealing redundancy and compensation among DILPs. PLoS ONE 3, e3721. doi:10.1371/journal.pone.0003721

Broughton, S. J., Piper, M. D., Ikeya, T., Bass, T. M., Jacobson, J., Driege, Y., Martinez, P., Hafen, E., Withers, D. J., Leevers, S. J., and Partridge, L. (2005). Longer lifespan, altered metabolism, and stress resistance in Drosophila from ablation of cells making insulin-like ligands. Proc. Natl. Acad. Sci. U.S.A. 102, 3105-3110.

Broughton, S. J., Slack, C., Alic, N., Metaxakis, A., Bass, T. M., Driege, Y., and Partridge, L. (2010). DILPproducing median neurosecretory the response of lifespan to nutrition. Aging Cell 9, 336-346. cells in the Drosophila brain mediate

In summary the Drosophila IPCs co-express DSKs and three DILPs, and the release of these peptides is likely to be coordinated. Thus, for any activation of the IPCs a cocktail of the two types of peptides is released into the circulation and it is likely that the action at different (or the same) targets is coordinated and orchestrates behavioral and metabolic events. At least after feeding the effect of the cocktail seems to be to induce satiety and a halted feeding at the same time as carbohydrate and lipid metabolism is altered to reallocate energy in the fly. This report is the first to identify a clear action of DSKs in regulation of feeding and satiety in Drosophila and also demonstrates mutual peptidergic feedback regulations of Dilp and Dsk gene transcription. Analysis of the distribution of the receptors for DSKs and DILPs would be helpful in the future to determine sites of peptide hormone action and to understand how the two types of signal could converge and possibly interact to regulate behavior and metabolism.

\section{ACKNOWLEDGMENTS}

The authors are grateful to S. Broughton, E. Hafen, R. Nichols, J. Park, J. A. Veenstra, the Bloomington Drosophila Stock Center, and the Vienna Drosophila RNAi Center for providing fly stocks and reagents. This study was supported by grants from the Swedish Research Council (VR) and the Carl Trygger Foundation (both to Dick R. Nässel).

Buch, S., Melcher, C., Bauer, M., Katzenberger, J., and Pankratz, M. J. (2008). Opposing effects of dietary protein and sugar regulate a transcriptional target of Drosophila insulinlike peptide signaling. Cell Metab. 7 , 321-332.

Cao, C., and Brown, M. R. (2001). Localization of an insulin-like peptide in brains of two flies. Cell Tissue Res. 304, 317-321.

Carvalho, G. B., Kapahi, P., Anderson, D. J., and Benzer, S. (2006). Allocrine modulation of feeding behavior by the sex peptide of Drosophila. Curr. Biol. 16, 692-696.

Chintapalli, V. R., Wang, J., and Dow, J. A. (2007). Using FlyAtlas to identify better Drosophila melanogaster models of human disease. Nat. Genet. 39, 715-720.

Clancy, D. J., Gems, D., Harshman, L. G., Oldham, S., Stocker, H., Hafen, E., Leevers, S. J., and Partridge, L. (2001). Extension of life-span by loss of CHICO, a Drosophila insulin receptor substrate protein. Science 292, 104-106.

Cognigni, P., Bailey, A. P., and MiguelAliaga, I. (2011). Enteric neurons and systemic signals couple nutritional and reproductive status with intestinal homeostasis. Cell Metab. 13, 92-104.

Colombani, J., Andersen, D. S., and Leopold, P. (2012). Secreted peptide Dilp8 coordinates Drosophila tissue growth with developmental timing. Science 336, 582-585.

Dagher, A. (2012). Functional brain imaging of appetite. Trends Endocrinol. Metab. 23, 250-260.

de la Rosa, E. J., and de Pablo, F. (2011). Proinsulin: from hormonal precursor to neuroprotective factor. Front. Mol. Neurosci. 4:20 doi:10.3389/fnmol.2011.00020

Dethier, V. (1976). The hungry Fly. Cambridge, MA: Harvard University Press.

Dockray, G. J. (2009). Cholecystokinin and gut-brain signalling. Regul. Pept. 155, 6-10.

Downer, K. E., Haselton, A. T., Nachman, R. J., and Stoffolano, J. G. Jr. (2007). Insect satiety: sulfakinin localization and the effect of drosulfakinin on protein and carbohydrate ingestion in the blow fly, Phormia regina (Diptera: Calliphoridae). J. Insect Physiol. 53, 106-112.

Duttlinger, A., Berry, K., and Nichols, R. (2002). The different effects of three Drosophila melanogaster dFMRFamide-containing peptides on crop contractions suggest these structurally related peptides do not play redundant functions in gut. Peptides 23, 1953-1957.

Edgecomb, R. S., Harth, C. E., and Schneiderman, A. M. (1994). Regulation of feeding behavior in adult Drosophila melanogaster varies with 
feeding regime and nutritional state. J. Exp. Biol. 197, 215-235.

Enell, L. E., Kapan, N., Söderberg, J. A., Kahsai, L., and Nässel, D. R. (2010). Insulin signaling, lifespan and stress resistance are modulated by metabotropic GABA receptors on insulin producing cells in the brain of Drosophila. PLoS ONE 5, e15780. doi:10.1371/journal.pone.0015780

Fontana, L., Partridge, L., and Longo, V. D. (2010). Extending healthy life span - from yeast to humans. Science 328, 321-326.

Garelli, A., Gontijo, A. M., Miguela, V., Caparros, E., and Dominguez, M. (2012). Imaginal discs secrete insulin-like peptide 8 to mediate plasticity of growth and maturation. Science 336, 579-582.

Géminard, C., Rulifson, E. J., and Leopold, P. (2009). Remote control of insulin secretion by fat cells in Drosophila. Cell Metab. 10, 199-207.

Giannakou, M. E., Goss, M., Junger, M. A., Hafen, E., Leevers, S. J., and Partridge, L. (2004). Longlived Drosophila with overexpressed dFOXO in adult fat body. Science $305,361$.

Giannakou, M. E., and Partridge, L. (2007). Role of insulin-like signalling in Drosophila lifespan. Trends Biochem. Sci. 32, 180-188.

Grandison, R. C., Piper, M. D., and Partridge, L. (2009). Amino-acid imbalance explains extension of lifespan by dietary restriction in Drosophila. Nature 462, 1061-1064.

Grönke, S., Clarke, D. F., Broughton, S., Andrews, T. D., and Partridge, L. (2010). Molecular evolution and functional characterization of Drosophila insulin-like peptides. PLoS Genet. 6, e1000857. doi:10.1371/journal.pgen.1000857

Hauser, F., Cazzamali, G., Williamson, M., Blenau, W., and Grimmelikhuijzen, C. J. (2006). A review of neurohormone GPCRs present in the fruitfly Drosophila melanogaster and the honey bee Apis mellifera. Prog. Neurobiol. 80, 1-19.

Hergarden, A. C., Tayler, T. D., and Anderson, D. J. (2012). AllatostatinA neurons inhibit feeding behavior in adult Drosophila. Proc. Natl. Acad. Sci. U.S.A. 109, 3967-3972.

Hwangbo, D. S., Gershman, B., Tu, M. P., Palmer, M., and Tatar, M. (2004). Drosophila dFOXO controls lifespan and regulates insulin signalling in brain and fat body. Nature 429 , 562-566.

Ikeya, T., Galic, M., Belawat, P., Nairz, K., and Hafen, E. (2002). Nutrientdependent expression of insulin-like peptides from neuroendocrine cells in the CNS contributes to growth regulation in Drosophila. Curr. Biol. 12, 1293-1300.

Ja, W. W., Carvalho, G. B., Zid, B. M., Mak, E. M., Brummel, T., and Benzer, S. (2009). Waterand nutrient-dependent effects of dietary restriction on Drosophila lifespan. Proc. Natl. Acad. Sci. U.S.A. 106, 18633-18637.

Janssen, T., Meelkop, E., Lindemans, M., Verstraelen, K., Husson, S. J., Temmerman, L., Nachman, R. J., and Schoofs, L. (2008). Discovery of a cholecystokinin-gastrinlike signaling system in nematodes. Endocrinology 149, 2826-2839.

Karpac, J., Hull-Thompson, J., Falleur, M., and Jasper, H. (2009). JNK signaling in insulin-producing cells is required for adaptive responses to stress in Drosophila. Aging Cell 8, 288-295.

Kenyon, C., Chang, J., Gensch, E., Rudner, A., and Tabtiang, R. (1993). A C. elegans mutant that lives twice as long as wild type. Nature 366, 461-464.

Kubiak, T. M., Larsen, M. J., Burton, K. J., Bannow, C. A., Martin, R. A., Zantello, M. R., and Lowery, D. E. (2002). Cloning and functional expression of the first Drosophila melanogaster sulfakinin receptor DSK-R1. Biochem. Biophys. Res. Commun. 291, 313-320.

Lee, G., and Park, J. H. (2004). Hemolymph sugar homeostasis and starvation-induced hyperactivity affected by genetic manipulations of the adipokinetic hormone-encoding gene in Drosophila melanogaster. Genetics 167, 311-323.

Lee, K. S., Kwon, O. Y., Lee, J. H., Kwon, K., Min, K. J., Jung, S. A., Kim, A. K., You, K. H., Tatar, M., and Yu, K. (2008). Drosophila short neuropeptide $\mathrm{F}$ signalling regulates growth by ERK-mediated insulin signalling. Nat. Cell Biol. 10, 468-475.

Lee, K. S., You, K. H., Choo, J. K., Han, Y. M., and Yu, K. (2004). Drosophila short neuropeptide $\mathrm{F}$ regulates food intake and body size. J. Biol. Chem. 279, 50781-50789.

Liddle, R. A., Morita, E. T., Conrad, C. K., and Williams, J. A. (1986). Regulation of gastric emptying in humans by cholecystokinin. J. Clin. Invest. 77, 992-996.

Lingo, P. R., Zhao, Z., and Shen, P. (2007). Co-regulation of coldresistant food acquisition by insulinand neuropeptide Y-like systems in Drosophila melanogaster. Neuroscience $148,371-374$.

Livak, K. J., and Schmittgen, T. D. (2001). Analysis of relative gene expression data using real-time quantitative PCR and the 2(-Delta Delta $\mathrm{C}(\mathrm{T})$ ) method. Methods 25 , 402-408.

Maestro, J. L., Aguilar, R., Pascual, N., Valero, M. L., Piulachs, M. D., Andreu, D., Navarro, I., and Belles, X. (2001). Screening of antifeedant activity in brain extracts led to the identification of sulfakinin as a satiety promoter in the German cockroach. Are arthropod sulfakinins homologous to vertebrate gastrinscholecystokinins? Eur. J. Biochem. 268, 5824-5830.

McMinn, J. E., Baskin, D. G., and Schwartz, M. W. (2000). Neuroendocrine mechanisms regulating food intake and body weight. Obes. Rev. 1 , 37-46.

Melcher, C., Bader, R., and Pankratz, M. J. (2007). Amino acids, taste circuits, and feeding behavior in Drosophila: towards understanding the psychology of feeding in flies and man. $J$. Endocrinol. 192, 467-472.

Melcher, C., and Pankratz, M. J. (2005). Candidate gustatory interneurons modulating feeding behavior in the Drosophila brain. PLoS Biol. 3, e305. doi:10.1371/journal.pbio.0030305

Meunier, N., Belgacem, Y. H., and Martin, J. R. (2007). Regulation of feeding behaviour and locomotor activity by takeout in Drosophila. J. Exp. Biol. 210, 1424-1434.

Meyering-Vos, M., and Muller, A. (2007). RNA interference suggests sulfakinins as satiety effectors in the cricket Gryllus bimaculatus. J. Insect Physiol. 53, 840-848.

Min, K. J., Yamamoto, R., Buch, S., Pankratz, M., and Tatar, M. (2008). Drosophila lifespan control by dietary restriction independent of insulin-like signaling. Aging Cell 7, 199-206.

Moran, T. H. (2009). Gut peptides in the control of food intake. Int. J. Obes. 33, 7-10.

Moran, T. H., and Dailey, M. J. (2009). Minireview: gut peptides: targets for antiobesity drug development? Endocrinology 150, 2526-2530.

Moran, T. H., Katz, L. F., Plata-Salaman, C. R., and Schwartz, G. J. (1998). Disordered food intake and obesity in rats lacking cholecystokinin A receptors. Am. J. Physiol. 274, R618-R625.

Murphy, K. G., and Bloom, S. R. (2006) Gut hormones and the regulation of energy homeostasis. Nature 444 854-859.

Murphy, K. G., Dhillo, W. S., and Bloom, S. R. (2006). Gut peptides in the regulation of food intake and energy homeostasis. Endocr. Rev. 27, 719-727.
Nachman, R. J., Holman, G. M., Cook, B. J., Haddon, W. F., and Ling, N. (1986a). Leucosulfakinin-II, a blocked sulfated insect neuropeptide with homology to cholecystokinin and gastrin. Biochem. Biophys. Res. Commun. 140, 357-364.

Nachman, R. J., Holman, G. M., Haddon, W. F., and Ling, N. (1986b). Leucosulfakinin, a sulfated insect neuropeptide with homology to gastrin and cholecystokinin. Science 234, 71-73.

Nachman, R. J., Holman, G. M., and Haddon, W. F. (1988). Structural aspects of gastrin/CCK-like insect leucosulfakinins and FMRF-amide. Peptides 9(Suppl. 1), 137-143.

Nässel, D. R., and Winther, Å. M. (2010). Drosophila neuropeptides in regulation of physiology and behavior. Prog. Neurobiol. 92, 42-104.

Nichols, R. (1992). Isolation and expression of the Drosophila drosulfakinin neural peptide gene product, DSK-I. Mol. Cell. Neurosci. 3, 342-347.

Nichols, R., Egle, J. P., Langan, N. R., and Palmer, G. C. (2008). The different effects of structurally related sulfakinins on Drosophila melanogaster odor preference and locomotion suggest involvement of distinct mechanisms. Peptides 29, 2128-2135.

Nichols, R., and Lim, I. A. (1996). Spatial and temporal immunocytochemical analysis of drosulfakinin (Dsk) gene products in the Drosophila melanogaster central nervous system. Cell Tissue Res. 283, 107-116.

Nichols, R., Mccormick, J., and Lim, I. (1997a). Dromyosuppressin and drosulfakinin, two structurally related Drosophila neuropeptides, are uniquely expressed in the adult central nervous system. Ann. N. Y. Acad. Sci. 814, 315-318.

Nichols, R., McCormick, J., and Lim, I. (1997b). Multiple antigenic peptides designed to structurally related Drosophila peptides. Peptides 18, 41-45.

Nichols, R., Schneuwly, S. A., and Dixon, J. E. (1988). Identification and characterization of a Drosophila homologue to the vertebrate neuropeptide cholecystokinin. J. Biol. Chem. 263, 12167-12170.

Nitabach, M. N., Blau, J., and Holmes, T. C. (2002). Electrical silencing of Drosophila pacemaker neurons stops the free-running circadian clock. Cell 109, 485-495.

Palmer, G. C., Tran, T., Duttlinger, A., and Nichols, R. (2007). The drosulfakinin 0 (DSK 0) peptide encoded in the conserved Dsk gene affects adult Drosophila melanogaster crop 
contractions. J. Insect Physiol. 53, 1125-1133.

Park, D., Veenstra, J. A., Park, J. H., and Taghert, P. H. (2008). Mapping peptidergic cells in Drosophila: where DIMM fits in. PLoS ONE 3, e1896. doi:10.1371/journal.pone. 0001896

Partridge, L., and Gems, D. (2002). Mechanisms of ageing: public or private? Nat. Rev. Genet. 3, 165-175.

Partridge, L., Piper, M. D., and Mair, W. (2005). Dietary restriction in Drosophila. Mech. Ageing Dev. 126, 938-950.

Ribeiro, C., and Dickson, B. J. (2010). Sex peptide receptor and neuronal TOR/S6K signaling modulate nutrient balancing in Drosophila. Curr. Biol. 20, 1000-1005.

Rulifson, E. J., Kim, S. K., and Nusse, R. (2002). Ablation of insulinproducing neurons in flies: growth and diabetic phenotypes. Science 296, 1118-1120.

Sandoval, D., Cota, D., and Seeley, R. J. (2008). The integrative role of CNS fuel-sensing mechanisms in energy balance and glucose regulation. Annu. Rev. Physiol. 70, 513-535.

Slack, C., Werz, C., Wieser, D., Alic, N., Foley, A., Stocker, H., Withers, D. J., Thornton, J. M., Hafen, E., and Partridge, L. (2010). Regulation of lifespan, metab- olism, and stress responses by the Drosophila SH2B protein, Lnk. PLoS Genet. 6, e1000881. doi:10.1371/journal.pgen.1000881

Staljanssens, D., Azari, E. K., Christiaens, O., Beaufays, J., Lins, L., Van Camp, J., and Smagghe, G. (2011). The CCK(-like) receptor in the animal kingdom: functions, evolution and structures. Peptides 32, 607-619.

Strader, A. D., and Woods, S. C. (2005). Gastrointestinal hormones and food intake. Gastroenterology 128, 175-191.

Tatar, M., Bartke, A., and Antebi, A. (2003). The endocrine regulation of aging by insulin-like signals. Science 299, 1346-1351.

Tatar, M., Kopelman, A., Epstein, D., Tu, M. P., Yin, C. M., and Garofalo, R. S. (2001). A mutant Drosophila insulin receptor homolog that extends life-span and impairs neuroendocrine function. Science 292, 107-110.

Wei, Z., Baggerman, G. R. J. N., Goldsworthy, G., Verhaert, P., De Loof, A., and Schoofs, L. (2000). Sulfakinins reduce food intake in the desert locust, Schistocerca gregaria. J. Insect Physiol. 46, 1259-1265.

Wicher, D., Derst, C., Gautier, H., Lapied, B., Heinemann, S. H., and Agricola, H. J. (2007). The satiety signaling neuropeptide perisulfakinin inhibits the activity of central neurons promoting general activity. Front. Cell. Neurosci. 1:3. doi:10.3389/neuro.03.003.2007

Woods, S. C., and D'Alessio, D. A. (2008). Central control of body weight and appetite. J. Clin. Endocrinol. Metab. 93, S37-S50.

Woods, S. C., Schwartz, M. W., Baskin, D. G., and Seeley, R. J. (2000). Food intake and the regulation of body weight. Annu. Rev. Psychol. 51, 255-277.

Wu, Q., and Brown, M. R. (2006). Signaling and function of insulinlike peptides in insects. Annu. Rev. Entomol. 51, 1-24.

Wu, Q., Wen, T., Lee, G., Park, J. H., Cai, H. N., and Shen, P. (2003). Developmental control of foraging and social behavior by the Drosophila neuropeptide Y-like system. Neuron $39,147-161$.

Wu, Q., Zhang, Y., Xu, J., and Shen, P. (2005a). Regulation of hungerdriven behaviors by neural ribosomal S6 kinase in Drosophila. Proc. Natl. Acad. Sci. U.S.A. 102, 13289-13294.

Wu, Q., Zhao, Z., and Shen, P. (2005b). Regulation of aversion to noxious food by Drosophila neuropeptide Yand insulin-like systems. Nat. Neurosci. 8, 1350-1355.
Wynne, K., Stanley, S., Mcgowan, B., and Bloom, S. (2005). Appetite control. J. Endocrinol. 184, 291-318.

Conflict of Interest Statement: The authors declare that the research was conducted in the absence of any commercial or financial relationships that could be construed as a potential conflict of interest.

Received: 12 May 2012; paper pending published: 14 June 2012; accepted: 15 August 2012; published online: 31 August 2012.

Citation: Söderberg JAE, Carlsson MA and Nässel DR (2012) Insulin-producing cells in the Drosophila brain also express satiety-inducing cholecystokinin-like peptide, drosulfakinin. Front. Endocrin. 3:109. doi: 10.3389/fendo.2012.00109

This article was submitted to Frontiers in Neuroendocrine Science, a specialty of Frontiers in Endocrinology.

Copyright (ㄷ) 2012 Söderberg, Carlsson and Nässel. This is an open-access article distributed under the terms of the Creative Commons Attribution License, which permits use, distribution and reproduction in other forums, provided the original authors and source are credited and subject to any copyright notices concerning any third-party graphics etc. 